\title{
Things may not be as expected: Surprising findings when updating workload at the Wits Human Research Ethics Committee (Medical)
}

\author{
P Cleaton-Jones, ${ }^{1}$ MB BCh, PhD, DSc (Dent), FCD; E S Grossman, ${ }^{2}$ BSc Hons, MSc (Dent), PhD \\ 'Steve Biko Centre for Bioethics, School of Clinical Medicine, Faculty of Health Sciences, University of the Witwatersrand, Johannesburg, South Africa \\ ${ }^{2}$ PO Box 14, Cannon Rocks, 6186 South Africa
}

Corresponding author: P Cleaton-Jones (pcleatonjones@gmail.com)

\begin{abstract}
Objectives. To compare numbers of applications to the University of the Witwatersrand Human Research Ethics Committee (Medical) for clearance by the full committee during 2011 - 2013; to see the proportion of clinical Master's applications in 2013 and to look for the influence of eight variables in applications reviewed from January to June 2013.

Methods. A retrospective extraction of data from committee minutes (2011-2013) and application forms (January - June 2013) was done. Statistical analysis was completed using SAS for Windows (version 9.4). Variables examined were committee decision, choice of research method, supervision or not, supervisors' research degree, supervisors' publication group, university administrative entity, registered degree and month of approval after first review.

Results. Total numbers were 685 (2011), 845 (2012, a 23.4\% increase from 2011) and 769 (2013, a 9.0\% decrease on the previous year). In $2013,22 \%$ of applications were for clinical Master's degrees required by the Health Professions Council of South Africa (HPCSA) for specialist registration. A number of cross-tabulations of variables are presented. Logistic regression analysis (Proc Catmod) showed that three variables significantly influenced the committee's initial review decision, namely school $(p=0.03)$, applicants' registered degree $(p=0.01)$ and the research method chosen $(p=0.03)$. The month of committee approval was also significantly affected by school $(p=0.002)$. Preferred research methodologies for supervised and independent research applications differed within and between schools.

Conclusion. A predicted continuous increase in number of applications from 2011 to 2013 did not happen for unknown reasons. Research method, school, and registered degree significantly influenced the committee's decision at the initial review of applications. For clinical Masters, and other Masters, a supervisor's degree had no effect on the committee's decision at the initial review of applications; however undergraduate and honours applicants having supervisors without a research degree had more than double the approval rate at first review than when supervisors had either a Doctorate or a Master's $(p=0.008)$. Supervisors' possession of a research degree did not increase approval rate of applications nor did a supervisor's publication grouping.
\end{abstract}

S Afr J BL 2015;8(1):14-21. DOI:10.7196/SAJBL.339

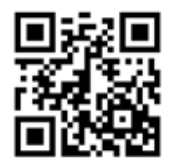

In 2011 the Health Professions Council of South Africa (HPCSA) brought in a new requirement for the registration of clinical specialists in South Africa namely the completion of '.. .. a relevant research study ... reported in the format of a dissertation. ${ }^{[1]}$

Since the National Health Act requires health research studies to be approved by a '... registered health research ethics committee, which is registered with the National Health Research Ethics Council ...., ${ }^{[2]}$ the Wits Human Research Ethics Committee (Medical) (Wits HREC (Medical)) began planning for an increase in application numbers from registrars in medicine and dentistry enrolled for the MMed and MDent degrees which fulfill the new HPCSA requirement. Such pre-emptive forward planning recognises that the facilitation of ethical conduct among researchers is an institutional governance issue which should best be imbedded within the institution's broader governance framework. ${ }^{[3]}$ In addition, transparent, visible preparedness goes a long way to improving the relationship between researchers and ethics committees.
At the time, based on the numbers of specialist registrars in the Faculty of Health Sciences, it was estimated that there would be 250 extra applications for ethics clearance per year from 2012 probably until 2015 when a plateau could be expected. ${ }^{[4]}$ Therefore, additional administrative staff and streamlining of procedures were put in place to meet the predicted upswing in applications. Concurrently, universities have extended their efforts to escalate the numbers and quality of candidates to meet the high-level skills demanded of our emerging economy. Recommendations highlighted in the 2011 National Development Plan: Vision for 2030 proposes that the number of $\mathrm{PhD}$ graduates rises fourfold by $2030 .{ }^{[5]}$ This, in turn, will require a concomitant increase in Masters candidates to supply the PhD pipeline ${ }^{[6]}$ over and above the number of clinical Master's envisioned by the HPCSA requirement. All these candidates, be they for a specialist clinical qualification, conventional Masters or $\mathrm{PhD}$, will probably ask for advice from their supervisors about ethical approval requirements laid down by their institution. ${ }^{[6]}$ In addition, postgraduate completion has been directly 
linked to the level of research activity within the postgraduate environment ${ }^{[8]}$ which by extension, encompasses supervisor research experience. For this reason a number of pertinent variables were included in the study to assess their influence on ethics application success, committee recommendation and time taken for approval. These variables were: qualifications and publication record of the supervisor; school of applicant origin; type of research method and degree for which the research is intended (if any). In the case of supervisor publication record, a threshold of four or more publications was used as an indicator of independent research expertise. ${ }^{[9]}$

The current study was undertaken with three objectives:

- To assess the total number of general research applications evaluated by the full HREC (Medical) from 2011 through 2013 and to substantiate or refute predicted changes from year to year

- To determine the proportion of clinical Master's applications (MMed, MDent) of all applications in 2013

- To examine trends in types of applications and influencing variables in applications reviewed in January through June 2013.

\section{Methods}

An audit of applications to the Wits HREC (Medical) was undertaken under ethics clearance from the committee (clearance M12014). Source documents were minutes of monthly meetings 2011 - 2013, expedited application reports for 2013 and application forms for January to June 2013. Sponsored clinical trials submitted through the Wits Research Consortium ethics secretariat were excluded as were applications for waivers from ethics clearance or case reports in journals or at congresses. The latter two are managed at chair level, not by the full committee, and number about 50 waivers and 25 case reports per year.

The standard procedure of the committee is as follows. After applications have been received by the monthly deadline (usually the seventh of each month) they are scrutinised by a chair and subdivided into:

- expedited (retrospective clinical record reviews, or secondary data analyses of established databases)

- regular applications.

All the expedited applications are allocated to a chair and one committee member for preparation of a concise standardised report to be tabled for the committee at each monthly meeting, the last Friday of the month. This report has the following headings - applicant name, department or organisation, title of proposed study, type of study, dates of study data collection, permissions to do the study, data sheet showing the data to be collected, and any comments which include the registered degree if present. The final section is a recommendation to the committee under three headings:

- approve (if all requirements are fulfilled)

- approve subject to conditions (e.g. provision of written permission from a hospital CEO to do the study)

- for discussion by the full committee to make a decision.

A global decision is made for recommended approvals for the first two bullet points above; applications in the discussion group are each evaluated as regular applications. Administrative procedures take approximately 10 - 14 working days to convey committee decisions to an applicant. Time taken to obtain approval, subject to conditions or amendments, relies on speed of feedback and compliance by applicants before final clearance can be issued. From January 2013 the type of a higher degree linked to an application has been recorded for possible auditing.

Publication record for each supervisor or independent researcher was obtained by searching PubMed using the surname and initials of the person. Qualifications of these individuals were obtained from university records in the public domain.

Statistical analysis was completed using SAS for Windows (version 9.4, Cary, NC, USA). Descriptive statistics were used as well as $\chi^{2}$-test (initial screening) and logistic regression analysis (Proc Catmod with maximum likelihood estimates) as the definitive test. The $p$-value for statistical significance was set at $p<0.05$ and $p$-values shown are for the logistic regression analysis. Graphs were drawn using Prism (Version 4, GraphPad Software Inc., San Diego, CA, USA).

\section{Results \\ Numbers of applications 2011 - 2013}

The trends in application numbers for 2011 through 2013 are shown by month in Fig. 1 . The wave-like monthly pattern is influenced by departmental deadlines for submission of research proposals, grant application deadlines, university vacations and public holidays. Easter usually closes the university first term and is regarded as a strategic academic calendar milestone. Based on an estimated additional 250 applications per year from $2011^{[4]}$ the expected increase to 2012 was from 685 to 935 (36\%) and for 2012 to 2013 from 935 to 1185 (27\%). Actual

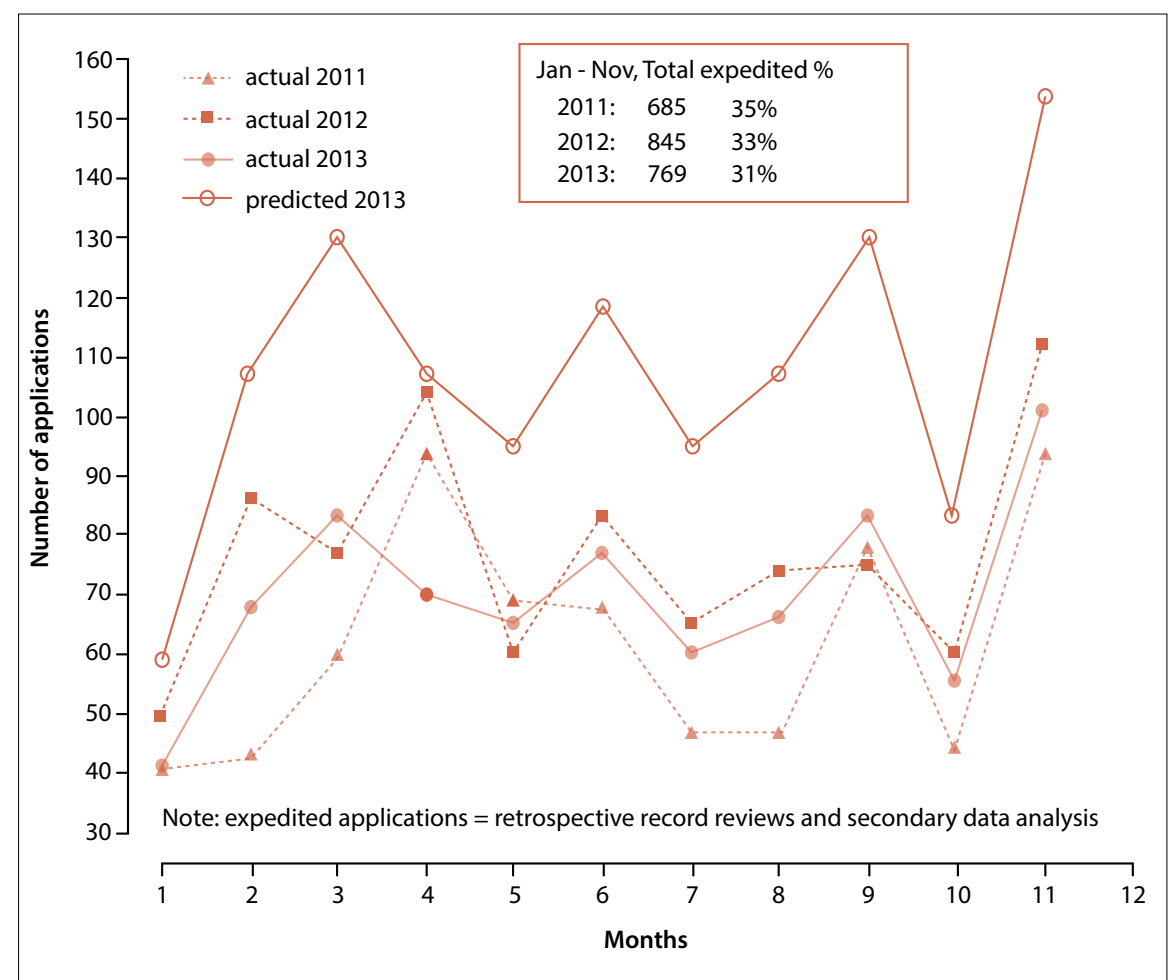

Fig 1. Pattern of actual applications by month for 2011 - 2013 and predicted number for 2013 assuming the same proportion per month as the actual applications in 2013. 
Table 1. Clinical Masters (MDent / MMed) and other applications by type of review evaluated by the full HREC (Medical) in 2013

\begin{tabular}{|c|c|c|c|c|c|c|c|c|c|}
\hline \multirow[b]{3}{*}{ Category } & \multicolumn{9}{|c|}{ Type of reviews } \\
\hline & \multicolumn{3}{|c|}{ Expedited } & \multicolumn{3}{|c|}{ Regular } & \multicolumn{3}{|c|}{ Total } \\
\hline & $n$ & col \% & row \% & $n$ & col \% & row \% & $n$ & col \% & row\% \\
\hline MDent / MMed & 94 & 39 & 55 & 78 & 15 & 45 & 172 & 22 & 100 \\
\hline Undergraduate / honours degrees / Other M degrees / PhD & 35 & 15 & 18 & 165 & 31 & 82 & 200 & 26 & 100 \\
\hline Not for higher degrees & 110 & 46 & 28 & 287 & 54 & 72 & 397 & 52 & 100 \\
\hline Total & 239 & 100 & & 530 & 100 & & 769 & 100 & \\
\hline
\end{tabular}

changes (2011 - 2012) were a $23 \%$ increase from 685 to 845 followed by a $9 \%$ decrease (20122013) from 845 to 769 . The total number seen in 2013 (769) was 416 applications less than the predicted 1185 for 2013. The predicted spread assuming the same proportion per month is shown in Fig. 1 and illustrates the potential increase in workload.

\section{Numbers of applications for clinical Masters and other degrees in 2013}

In 2013 it was possible to tabulate, from committee minutes, the purpose of applications throughout the year (Table 1). Clinical Master's candidates affected by the HPCSA regulation numbered 172/769 (22\%) of applications. Other degrees (undergraduate or honours) and other Masters and Doctorates, comprised $26 \%$ while the majority, $52 \%$, was not for higher degrees. Expedited applications (retrospective clinical record reviews and secondary data analyses numbered 239 (45\%). Within the three applicant categories the row percentage showed that clinical candidates had a slight preference for expedited applications; the other two categories had strong preferences for regular applications.

\section{Trends in applications: January - June 2013}

The rest of this article describes trends in the 407 applications reviewed for January through June 2013, for which anonymous detailed records were kept. Table 2 shows decision rates, at the initial review of an application, then the rates of final decisions including initial approvals and the outcome of revisions. Of the 407 applications during the 6-month study period, $24 \%$ were approved at the initial review, two-thirds needed minor revision, $4 \%$ required major revision, and $6 \%$ were not approved in the

Table 2. Decision rates for applications to full HREC (Medical) January - June 2013

\begin{tabular}{lcccc}
\hline & \multicolumn{4}{c}{ Decision at initial review } \\
\cline { 2 - 5 } Type of applications & $\begin{array}{c}\text { Approved } \\
\text { row \% }\end{array}$ & $\begin{array}{c}\text { Minor revision } \\
\text { row \% }\end{array}$ & $\begin{array}{c}\text { Major revision } \\
\text { row \% }\end{array}$ & $\begin{array}{c}\text { Not approved } \\
\text { row \% }\end{array}$ \\
\hline Expedited $n=127$ & 37 & 62 & 0 & 1 \\
Regular $n=280$ & 18 & 68 & 6 & 8 \\
Total $n=407$ & 24 & 66 & 4 & 6 \\
& \multicolumn{5}{c}{ Final decisions } \\
Type of applications & Approved & Removed from agenda & Not approved \\
row \% & \multicolumn{2}{c}{ row \% } \\
\hline Expedited $n=127$ & 95 & 5 & 0 \\
Regular $n=280$ & 78 & 22 & 0.4 \\
Total $n=407$ & 83 & 17 & 0.3
\end{tabular}

Table 3. Research method by cluster January - June 2013

\begin{tabular}{|c|c|c|c|c|c|c|}
\hline \multirow[b]{2}{*}{ Method } & & \multicolumn{2}{|c|}{ Independent research } & \multicolumn{3}{|c|}{ Supervised research } \\
\hline & & row \% & col \% & & row \% & col \% \\
\hline Epidemiology $n=64$ & & 28 & 19 & & 72 & 15 \\
\hline Intervention $n=48$ & & 33 & 17 & & 67 & 10 \\
\hline Interview / focus group $n=53$ & & 32 & 18 & & 68 & 12 \\
\hline Laboratory $n=46$ & & 22 & 11 & & 78 & 12 \\
\hline Observation $n=30$ & & 3 & 1 & & 97 & 9 \\
\hline Record review - prospective $n=24$ & & 37 & 10 & & 63 & 5 \\
\hline Record review - retrospective $n=106$ & & 10 & 12 & & 90 & 30 \\
\hline Secondary data analysis $n=64$ & & 32 & 12 & & 68 & 7 \\
\hline \multirow[t]{2}{*}{ Total $n=405^{*}$} & $n$ & row $\%$ & $\mathrm{col} \%$ & $n$ & row\% & $\mathrm{col} \%$ \\
\hline & 93 & 23 & 100 & 312 & 77 & 100 \\
\hline
\end{tabular}

form submitted. The final review increased approvals to $83 \%$, and lowered the number not approved to $0.3 \%$ but $17 \%$ were removed from the agenda for reasons of non-response (done at the end of three months after the first review month). Expedited applications had higher approval rates and a lower proportion removed from the agenda than regular applications.
The applicants were subdivided into two clusters; an independent research group with no supervisor, and a supervised research group consisting of students working towards a higher degree and individuals needing supervision but not towards a higher degree. Table 3 lists the eight research methods by rates of independent and supervised research overall. The most 


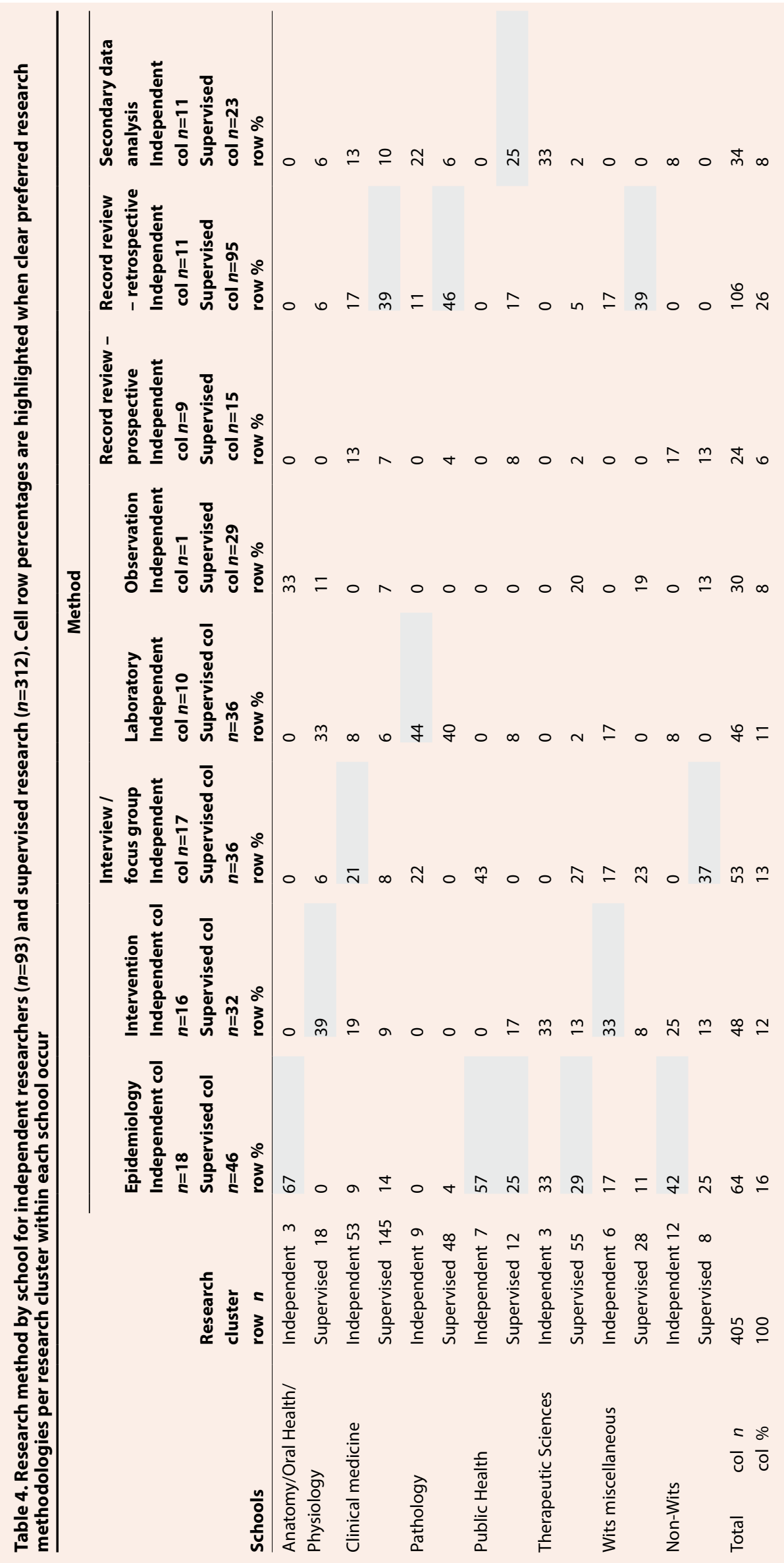

common method was a retrospective record review ( $n=106)$ followed by epidemiology and secondary data analysis both at $n=64$. Least frequent was observation $(n=$ 30). There were no statistically significant differences between research methods in the two clusters.

Next, the research method used was examined across seven academic groupings (schools) for independent researchers and for supervised researchers (Table 4). For independent researchers epidemiology showed the highest percentage in three groupings:

- The combination of the schools of Anatomical Sciences, Oral Health Sciences and Physiology

- Public Health

- Non-Wits applications.

Intervention was favoured by Wits miscellaneous applications; interview/ focus groups by Clinical Medicine and the School of Pathology preferred laboratory studies. An important caveat in Table 4 is the small sample sizes of the independent research methodologies, which is between 1 and 17, low for firm, statistically based conclusions. Supervised research had larger numbers (ranging from 15 to 95) utilising the research methods, thereby strengthening the rigour of conclusions. The comparison of percentages show distinct variations in preferences with independent researchers using research methodologies quite different from those used by supervised candidates within a single school.

Statistically significant influences on committee decision at initial review were weak for research method ( $p=0.03$; Table $5)$, strong for school $(p=0.003)$ and none for cluster.

In Table 5 the decision rates at initial review for the study methods are listed. For statistical analysis major revisions and 'not approved' decisions were combined into 'serious revision'. The highest approval rates were for retrospective record reviews, secondary data analyses and laboratory studies; these also had the lowest rates of serious revisions. Logistic regression analysis showed a strong statistical role of research method $(p=0.001)$ but no significance for cluster (supervised or independent research).

Rates of research method use by registered degree are shown in Table 6 . Within each degree group there is a spread of method 
choices. The highest rates are as follows: no degree - prospective record review; undergraduate degree - retrospective record review; honours degree - observation; clinical Master's - retrospective record review; other Masters - observation; and Doctorate laboratory. Initial review decisions (Table 7) show the highest approval rate for honours degrees $(57 \%)$ with a steady decline through to the lowest for Doctorates (14\%). The highest serious revision rate was for doctorates and the lowest for undergraduates. Statistically there was a strong influence of research method ( $p=0.002$ ) and a less powerful effect of registered degree $(p=0.01)$ on the initial review decision.
The effects of a supervisor research degree and publication group on initial review decisions are shown in Table 8. Faculty regulations require Doctoral students to be supervised by a person with a Doctorate; someone with a Masters may only be a co-supervisor. The four instances of the latter were excluded from the analysis. Approval rates by a supervisor's research degree ranged from 17 to $26 \%$ with irregular variations in approval rate for the type of registered degree (13 to 53\%). The only statistically significant influence was for the undergraduate and honours degrees where supervisors without a research degree had double the approval rate $(p=0.01)$ of supervisors with a research degree. This is
Table 5. Decision rates at initial review for all applicants by research method

\begin{tabular}{lccc}
\hline Method & $\begin{array}{c}\text { Approve } \\
\text { row \% }\end{array}$ & $\begin{array}{c}\text { Minor revision } \\
\text { row \% }\end{array}$ & $\begin{array}{c}\text { Serious revision } \\
\text { row \% }\end{array}$ \\
\hline Epidemiology $v=64$ & 14 & 69 & 17 \\
Intervention $n=48$ & 17 & 62 & 21 \\
$\begin{array}{l}\text { Interview / focus group } \\
n=53\end{array}$ & 19 & 70 & 11 \\
Laboratory $n=46$ & 33 & 65 & 23 \\
$\begin{array}{l}\text { Observation } n=30 \\
\text { Record review }- \\
\text { prospective } n=24\end{array}$ & 7 & 70 & 8 \\
$\begin{array}{l}\text { Record review }- \\
\text { retrospective } n=106\end{array}$ & 87 & 83 & 1 \\
$\begin{array}{l}\text { Secondary data analysis } \\
n=64\end{array}$ & 32 & 62 & 3 \\
\hline
\end{tabular}

\begin{tabular}{ccccccc}
\hline Total $n=405$ & $n$ & col $\%$ & $n$ & col \% & $n$ & col \% \\
\cline { 2 - 7 } & 96 & 24 & 270 & 67 & 39 & 9
\end{tabular}

Serious revision $=$ major revision + not approved probably due to simpler research projects. Candidates having a supervisor with a $\mathrm{PhD}$ were more likely to submit an application requiring serious revision compared to those whose supervisor had a Master's degree. No significant influence was found on approval rates for supervisors in the two publications groups.

Table 9 displays the month in which an application was approved by school grouping; the same month as the meeting is the ideal. Greater than four months after the first review month indicates no response forthcoming from the applicant. The greatest delay was in the non-Wits group (20\%) which also had the highest rate for no response. Absence of a response was lowest in Public Health (5\%) and Pathology (11\%), with the remaining school groups between 18 and $20 \%$. The highest approval rate in the same month was in Pathology. When the cumulative percentages, from the same month to the fourth after a committee meeting are examined, the Wits schools have three-quarters of applications approved by the third month. The only variable that influenced the rates was school $(p=0.002)$.

\section{Discussion}

The $23.4 \%$ increase in applications for 2011 to 2012 fitted fairly closely into the anticipated annual increase because of the new HPCSA requirements of completion of a dissertation in order to register as a clinical specialist. ${ }^{[1]}$ However, the $9 \%$ decrease from 2012 to 2013 was a surprise because the number of clinical Masters registrations in the Faculty of Health Sciences was the same

Table 6. Research method by registered degree January - June 2013

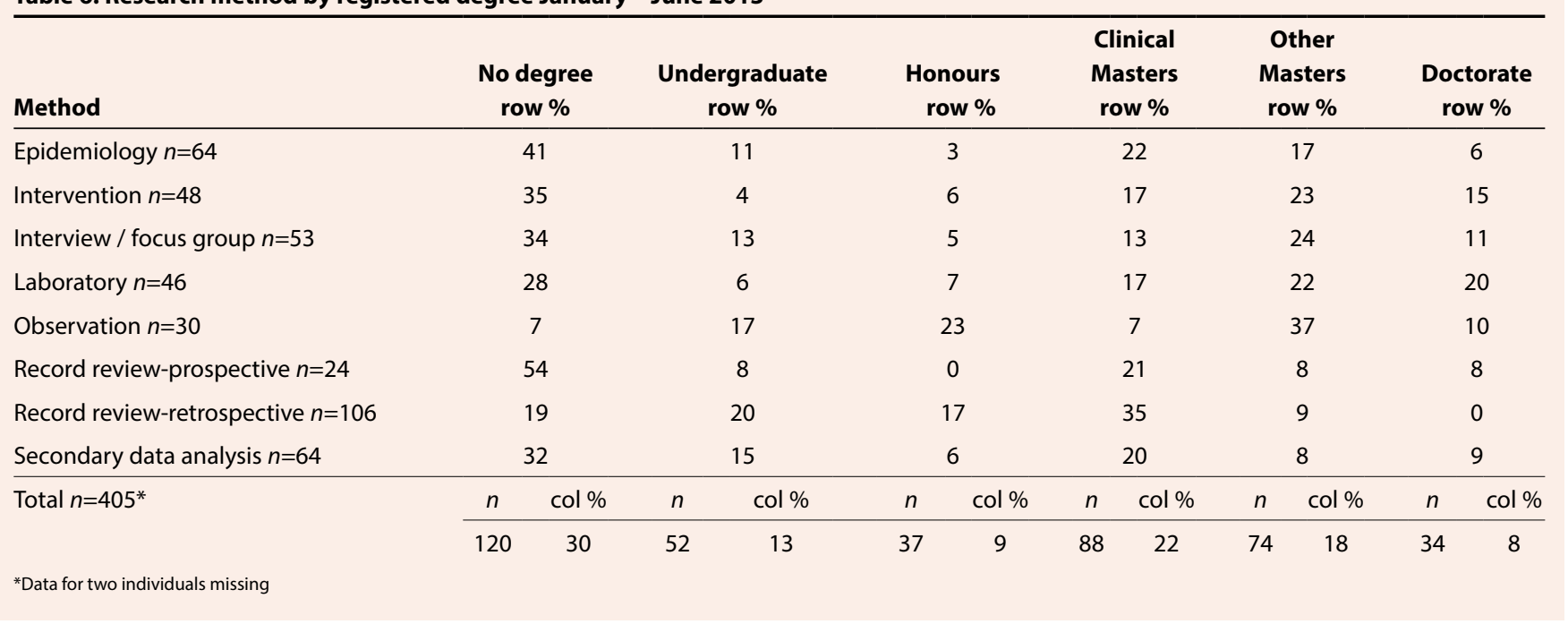


Table 7. Decision rates at initial review for all applicants by registered degree

\begin{tabular}{|c|c|c|c|c|c|c|}
\hline \multirow{2}{*}{$\frac{\text { Registered degree }}{\text { Not for degree } n=120}$} & \multicolumn{2}{|c|}{$\begin{array}{c}\text { Approve } \\
\text { row \% }\end{array}$} & \multicolumn{2}{|c|}{$\begin{array}{l}\text { Minor } \\
\text { revision } \\
\text { row \% }\end{array}$} & \multicolumn{2}{|c|}{$\begin{array}{l}\text { Serious } \\
\text { revision } \\
\text { row \% }\end{array}$} \\
\hline & \multicolumn{2}{|c|}{20} & \multicolumn{2}{|c|}{69} & \multicolumn{2}{|l|}{10} \\
\hline Undergraduate $n=52$ & \multicolumn{2}{|c|}{17} & \multicolumn{2}{|c|}{77} & \multicolumn{2}{|l|}{6} \\
\hline Honours $n=37$ & \multicolumn{2}{|c|}{57} & \multicolumn{2}{|c|}{35} & \multicolumn{2}{|l|}{8} \\
\hline Masters - clinical $n=89$ & \multicolumn{2}{|c|}{21} & \multicolumn{2}{|c|}{71} & \multicolumn{2}{|l|}{8} \\
\hline Masters - other $n=74$ & \multicolumn{2}{|c|}{23} & \multicolumn{2}{|c|}{66} & \multicolumn{2}{|l|}{11} \\
\hline Doctorate $n=35$ & \multicolumn{2}{|c|}{14} & \multicolumn{2}{|c|}{66} & \multicolumn{2}{|l|}{20} \\
\hline \multirow[t]{2}{*}{ Total $n=407$} & $n$ & $\mathrm{col} \%$ & $n$ & $\mathrm{col} \%$ & $n$ & $\mathrm{col} \%$ \\
\hline & 96 & 24 & 271 & 66 & 40 & 10 \\
\hline
\end{tabular}

Table 8. Decision rates at initial review for supervised applicants by research degree and by publication group of supervisor. Mean column percentages are shown in bold

\begin{tabular}{|c|c|c|c|c|c|c|}
\hline \multicolumn{2}{|c|}{ Supervisor's } & \multirow[b]{2}{*}{ Registered degree } & \multirow[b]{2}{*}{$n$} & \multicolumn{3}{|c|}{ Decision at initial review } \\
\hline $\begin{array}{l}\text { Supervisor } \\
\text { research } \\
\text { degree }\end{array}$ & $\boldsymbol{n}$ & & & $\begin{array}{l}\text { Approve } \\
\text { row \% }\end{array}$ & $\begin{array}{l}\text { Minor } \\
\text { revision } \\
\text { row \% }\end{array}$ & $\begin{array}{l}\text { Serious } \\
\text { revision } \\
\text { row \% }\end{array}$ \\
\hline \multirow{5}{*}{ Doctorate } & \multirow{5}{*}{113} & Doctorate & 30 & 13 & 67 & 20 \\
\hline & & Clinical Masters & 13 & 0 & 85 & 15 \\
\hline & & Other Masters & 34 & 32 & 47 & 21 \\
\hline & & Undergraduate / honours & 36 & 25 & 58 & 17 \\
\hline & & & & $18 \%$ & $64 \%$ & $18 \%$ \\
\hline \multirow{4}{*}{ Masters } & \multirow{4}{*}{148} & Clinical Masters & 59 & 25 & 66 & 9 \\
\hline & & Other Masters & 29 & 17 & 79 & 4 \\
\hline & & Undergraduate / honours & 56 & 22 & 71 & 7 \\
\hline & & & & $21 \%$ & $72 \%$ & $7 \%$ \\
\hline \multirow{4}{*}{ None } & \multirow{4}{*}{52} & Clinical Masters & 16 & 25 & 75 & 0 \\
\hline & & Other Masters & 4 & 0 & 100 & 0 \\
\hline & & Undergraduate / honours & 32 & 53 & 44 & 3 \\
\hline & & & & $26 \%$ & $73 \%$ & $1 \%$ \\
\hline \multicolumn{7}{|c|}{$\begin{array}{l}\text { Supervisor's } \\
\text { publication } \\
\text { group }\end{array}$} \\
\hline \multirow{5}{*}{\multicolumn{2}{|c|}{$\begin{array}{l}\geq 4 \text { publications } \\
n=154\end{array}$}} & Doctorate & 30 & 13 & 67 & 20 \\
\hline & & Clinical Masters & 47 & 21 & 75 & 4 \\
\hline & & Other Masters & 28 & 29 & 57 & 14 \\
\hline & & Undergraduate / honours & 49 & 21 & 63 & 16 \\
\hline & & & & $21 \%$ & $66 \%$ & $13 \%$ \\
\hline \multirow{5}{*}{\multicolumn{2}{|c|}{$\begin{array}{l}\leq 3 \text { publications } \\
n=156\end{array}$}} & Doctorate & 0 & 0 & 0 & 0 \\
\hline & & Clinical Masters & 41 & 22 & 66 & 12 \\
\hline & & Other Masters & 40 & 23 & 67 & 10 \\
\hline & & Undergraduate / honours & 75 & 37 & 59 & 4 \\
\hline & & & & $27 \%$ & $64 \%$ & $9 \%$ \\
\hline
\end{tabular}

in 2012 and 2013; so far the reason for the decrease is unknown.

Of the 769 applications, clinical Masters comprised $22 \%$ almost equally split between expedited and regular applications. We had anticipated that the expedited type would proportionately be about double the regular sort for clinical Masters because of the relative ease of that type of study. There were almost equal numbers of applications from postgraduates and from individuals not attempting a higher degree.
Biomedical ethics approval is a very specific type of application and different to other research fields. This has been used to justify the extended times often encountered in the healthcare-based ethics approval process. For instance, Hunter ${ }^{[7]}$ reports that approximately $15 \%$ of medical applications receive approval immediately. By contrast, Doyle, Mullins and Cunningham ${ }^{[12]}$ report that a business school ethics committee approved $62 \%$ of applications immediately. Despite additional staffing and the introduction of procedural efficiencies, our results show that only $24 \%$ of applications got immediate approval at the monthly meeting during which applications are first reviewed (Table 2), rising to $34 \%$ in the same month as the committee meeting. By the second month after the initial assessment, two-thirds of applications had been approved and three-quarters by the third month (Table 9). This means that, allowing for the submission month prior to the initial meeting and the administrative procedures linked to clearance, most applicants are able to pursue their research four months after submitting their application, a finding corroborated by Clarke. ${ }^{[13]}$ Within the compressed time frames of clinical registrar training, a four-month down time in their research programme is onerous. Ideally, supervised research applications should be submitted well before research begins to allow optimal use of registrar training time frames; in reality this seldom happens. The lack of response from applicants, $17 \%$ by the fifth month, is a phenomenon previously seen. ${ }^{[4]}$ Discussions with other South African university research ethics committee chairs report the same pattern. The reasons are unknown but speculation suggests possible loss of interest in a project or inability to raise research funds. To the committee's knowledge such studies are not embarked upon without ethics approval.

Unfortunately the resources spent in terms of time and energy, for the $76 \%$ of applications which were returned for clarification or amendment, are heavy for both committee members and researchers. Additionally, the 'back-andforth' research ethics review and decision process also imposes further work on already overburdened faculty postgraduate supervisors. ${ }^{[1]]} \mathrm{A}$ conundrum often faced by our committee, when returning the $76 \%$ of applications for 'compliance problems ${ }^{[3]}$ has 
Table 9. Cumulative month of ethics approval in relation to committee meeting for all applicants by school

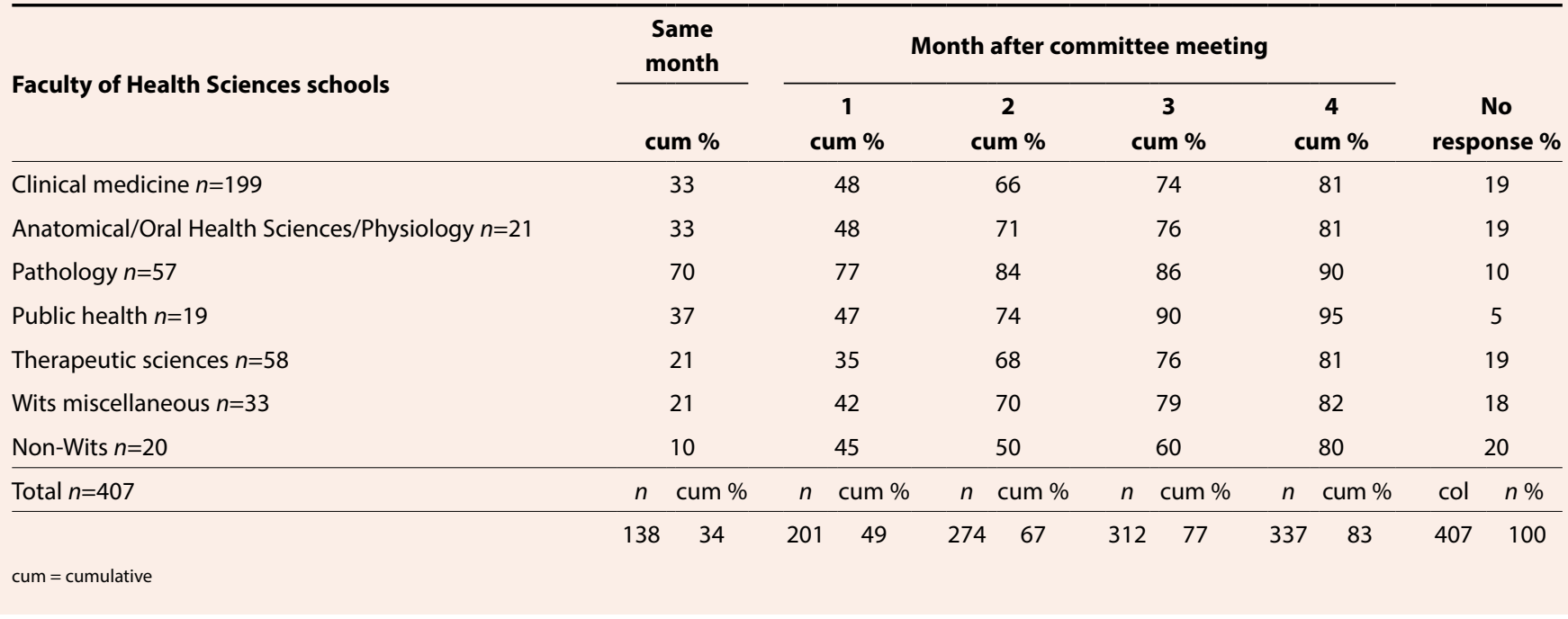

been described by Doyle et a[ ${ }^{[12]}$ as follows: 'Should poorly completed applications with multiple grammatical and typing errors, providing vague and/or contradictory information about what appears to be nevertheless a completely innocuous project be approved on the basis that there are no ethical issues involved? Should they be rejected on the basis that the applicants have failed to engage properly with the process and have demonstrated a lack of respect for research ethics review? Should the committee be concerned with ensuring that the researcher has demonstrated that he/she has taken the time to thoughtfully consider all potential harm that may be caused by the research by completing the application form carefully and comprehensively or should standard answers copied from other application forms that have been approved, suffice?' It is our experience that supervisors frequently sign applications that fit into Doyle et al's ${ }^{[12]}$ description, influenced we believe by time and deadlines as much as anything else. The Wits HREC (Medical) has yet to reach consensus on this conundrum when weighing up its dual accountabilities: firstly towards the university which, after all, bears the responsibilities of research conducted within it and secondly the postgraduates who entrust their intellectual growth and efficient throughput to the very same institution.

A statistically significant effect on the committee's initial review decision was found for three variables: research method (at two values depending on the variable grouping ( $p=0.03, p=0.002)$; school $(p=0.002)$ and registered degree $(p=0.01)$. Our view is that these variables are proxies for interactions of the variables studied and others not known. A particularly unexpected finding was that within the statistically significant effect of supervisors' research degree $(p=0.002)$, supervisors without a research degree (Masters or Doctorate) had the highest committee approval rate and lowest serious revision rate. Supervisors with a Doctorate had the lowest approval and highest serious revision rates. It had been anticipated that supervisors with a higher publication rate would have better committee decision results but this too was not seen. Perhaps the threshold for research expertise was set too low. The $\geq 4$ publications chosen was originally calculated in a review of postgraduates over 53 years; ; it showed that persons with that number of publications continued to do research in their lifetimes. Other speculative explanations include that supervisors with a PhD may be so busy that they have little time to spend with their postgraduates or may suggest supervision of particularly complicated projects. Likewise, having gained a $\mathrm{PhD}$, the supervisor may regard the ethics application procedure as a beneficial independent learning exercise and prefer to stand back to allow candidates to learn for themselves. Tilley ${ }^{[10]}$ raises the issue of supervisors who do not take the task of correctly completing an ethics application form seriously, thereby making the work of the ethics review board much more difficult when dealing with such cases involving postgraduates. Undergraduate research projects are generally at a lower level which may have influenced the higher approval rate seen with supervisors without a higher degree since such supervisors frequently gain initial experience aiding undergraduates.

It seems that having a supervisor with a PhD or with an independent research record does not mean a candidate is able to submit a competent application. Facilitation of the ethics approval process all depends on the ability and experience of the supervisor in understanding the nuances of the ethics process. Buttery, Richter and Filho ${ }^{[11]}$ opine that a supervisor with no or little experience adds nothing to the research process (and by extension obligations of ethical approval) as far as the student is concerned. Worse still, a poorlytrained supervisor compounds the effects of poor supervision by exacerbating rather than overcoming the complexity of ethical issues related to research. To overcome such problems Hunter ${ }^{[6]}$ suggests that a supervisor should be encouraged to attend ethics meetings with the candidate as this improves the chances of applications being approved. This is echoed by Tilley ${ }^{[10]}$ who suggests that understanding how to shape an ethics application that would be approved in an efficient manner will be greatly beneficial to all stakeholders. Our belief is that supervisors need formal training and should begin by being a co-supervisor with an experienced supervisor for perhaps two projects before appointment as the sole supervisor.

The last surprising finding of this study was that research methodologies used in supervised research were quite different to those used by independent researchers within the same school. This implies that two deliberate research tracks are at play. In the postgraduate research track, research topics are tailored to optimally meet the requirements of the degree. Pertinently, the retrospective 
record review is regarded as a 'simple' study method and was utilised by the majority of clinical Masters candidates, a finding supported by Clarke. ${ }^{[13]}$ On the other hand an independent research track fulfills either a school research programme or follows a personal research interest requiring more complex research strategies. It is also not clear whether limited research resources are preferentially being funnelled towards postgraduate research outputs to meet university targets of increasing graduation throughputs. Exactly what knock-on effect this has on the current paradigm, where the creation of new knowledge is a cornerstone of the goals of a knowledge-based economy, can be only speculated upon. It would be interesting if our finding of dichotomous research methodologies supporting independent and supervised research is substantiated by others.

Finally, this article does not deal with reasons for the HREC (Medical) not approving applications at first review; an earlier publication gives insight into this matter. ${ }^{[14]}$

\section{Conclusion}

The results of a retrospective examination of applications to the Wits HREC (Medical) have shown some surprising features. A predicted continuous increase in number of applications from 2011 to 2013, based on an HPCSA requirement for a dissertation by clinicians to register as specialists, did not happen in spite of no change in numbers of registered clinical postgraduates. While statistically significant influences on the decision at first review of applications were found for method of research, school, and registered degree, expected roles of categorising supervisors by research degree held and publication grouping had no influence other than a minor one for undergraduate/honours degree applicants. This article shows that ethics application data can be used as a barometer to indicate early grassroots movements by faculty to meet demands in postgraduate throughput and as a feeler to shifting faculty research currents. Given the current emphasis on research output and pressure on staff, including inexperienced individuals, to supervise research we recommend completion of at least a short basic training in supervision including what ethics committees look for in applications. Hopefully this would help supervisors, supervisees and ethics committees and increase the speed though the latter.
Acknowledgements. We are grateful to the HREC (Medical) secretariat, Mrs Anisa Keshav and Ms Zanele Ndlovu for assistance with tracing some application details and to Prof. Paul Fatti, emeritus professor of statistics at the University of the Witwatersrand for his statistical advice.

\section{References}

1. Health Professions Council of South Africa: Subcommittee for Postgraduate Education and Training. New requirements for the registration of specialists in South Africa. 2012 http://www.hpsa.org.sa/downloads/medical_dental/new requirements_for_registration_of_specialists_in_sa.pdf (accessed 24 February 2011).

2. Republic of South Africa, National Health Act, No. 61. Government Gazette 2004. http://www.section27.org.za/wp-content/uploads/2010/03/national-health-act. pdf (accessed 25 November 2013).

3. Allen G. Getting beyond form filling: The role of institutional governance in human research ethics. J Acad Ethics 2008;6(2):105-116. [http://dx.doi.org/10.1007/ s10805-008-9057-9]

4. Cleaton-Jones P. Applications and secretariat workload at the University of the Witwatersrand Human Research Ethics Committee (Medical). S Afr J BL 2012;5(1):38-44.

5. Republic of South Africa. National Development Plan - Vision for 2030. Pretoria: The Presidency 2011. http://www.npconline.co.za/medialib/downloads/home/ NPC\%20National\%20Development\%20Plan\%20Vision\%202030\%20-lo-res.pdf. (accessed 27 May 2014).

6. Academy of Science of South Africa. The PhD Study. Pretoria: Academy of Science in South Africa, 2010.

7. Hunter D. A hands-on guide on obtaining research ethics approval. Postgrad Med J 2011; 87(1030):509-513. [http://dx.doi.org/10.1136/pgmj.2010.109348]

8. ParkC. The research student experience: Lessons from PRES. York: Higher Education Academy, 2009. http://www.heacademy.ac.uk/assets/York/documents/ourwork/ postgraduate/PRES2009.pdf (accessed 15 November 2010).

9. Grossman ES, Cleaton-Jones PE. What becomes of dental research trainees once they leave the Dental Research Institute? An analysis over 53 years. Eur J Dent Educ 2008;12(2):69-74. [http://dx.doi.org/10.1111/j.1600-0579.2008.00471.x]

10. Tilley SA. A troubled dance: Doing the work of research ethics review. J Acad Ethics 2008;6:91-104. [http://dx.doi.org/10.1080/03075079.2012.709495]

11. Buttery EA, Richter EM, Filho WF. An overview of the elements that influence efficiency in postgraduate supervisory practice. Int J Educ Management 2005;19:7-26. [http://dx.doi.org/10.4236/ce.2014.522214]

12. Doyle $E$, Mullins $M$, Cunningham $M$. Research ethics in a business school context: The establishment of a review committee and the primary issues of concern. J Acad Ethics 2010;8:43-66. [http://doi/10.1007/s10805-010-9108-x]

13. Clarke DL. Auditing the process of ethics approval for Master's degrees at a South African university. S Afr J BL 2014;7(1):23-25. [http://dx.doi.org/10.7196/ SAJBL.301]

14. Cleaton-Jones P. Process error rates in general research applications to the Human Research Ethics Committee (Medical) at the University of the Witwatersrand; a secondary data analysis. S Afr J BL 2010;3(1):20-24. 